\title{
Critical Speed Analysis of Fibre Reinforced Composite Rotor Embedded with Shape Memory Alloy Wires
}

\author{
K. GUPTA* \\ Mechanical Engineering Department, Indian Institute of Technology, Hauz Khas, New Delhi, 110016, India
}

(Received 24 April 1998; In final form 14 August 1998)

\begin{abstract}
In the present analysis, the fundamental natural frequency of a Jeffcott and a two-mass rotor with fibre reinforced composite shaft embedded with shape memory alloy (SMA) wires is evaluated by Rayleigh's procedure. The flexibility of rotor supports is taken into account. The effect of three factors, either singly or in combination with each other, on rotor critical speed is studied. The three factors are: (i) increase in Young's modulus of SMA (NITINOL) wires when activated, (ii) tension in wires because of phase recovery stresses, and (iii) variation of support stiffness by three times because of activation of SMA in rotor supports. It is shown by numerical examples that substantial variation in rotor critical speeds can be achieved by a combination of these factors which can be effectively used to avoid resonance during rotor coast up/down.
\end{abstract}

Keywords: Intelligent/smart rotors, Active control of rotors, Composite rotors with shape memory alloy wires, Vibration control during rotor coast up/down

\section{INTRODUCTION}

Shape memory alloys (SMA) have been commercially available since the past few decades, but their applications have been very limited, i.e. force and displacement actuators. Rogers (1990), suggested that SMA fibres could be embedded into conventional composites such as graphite/epoxy to control the structural response including static deformation, vibration, buckling and structural acoustic radiations and transmission. The behaviour of
SMA is governed by the diffusionless phase transformation between a high-temperature lowstrain austenite phase and a low-temperature highstrain martensite phase. The shape memory effect arises from the interplay of temperature and stress in the free energy of the alloy. A common SMA is 55-NITINOL, which is a nickel and titanium alloy. Its Young's modulus increases about four times when heated above its austenite transformation temperature. Also it can be trained to have a particular shape while in austenite phase. If it is

*Tel.: 0091-11-6861977. Ext. 3166. Fax: 0091-11-6362037. E-mail: kgupta@mech.iitd.ernet.in. 
cooled to its martensite phase and subjected to plastic deformation, it will return to its 'memorised' shape when heated above the austenite transformation temperature.

Recent developments (Singh et al., 1997) in Composite rotors have opened up tremendous possibilities of developing smart rotors by embedding SMA wires in fibre reinforced composite shafts. Baz and Chen (1993) have analysed a composite rotor embedded with NITINOL wires by theoretical and experimental means. Their results have shown a reduction of about $50 \%$ in vibration amplitudes by activating NITINOL wires. Nagaya et al. (1987) proposed the use of SMA in rotor supports to control the rotor critical speeds.

In the present work, a rotor made of fibre reinforced composite shaft embedded with NITINOL wires is analysed theoretically to estimate their effect on the rotor critical speed. A flexibly supported simple rotor with two identical masses mounted symmetrically about the midspan is considered. The effect of increase in stiffness (Young's modulus) and tension in wires due to phase recovery stresses when wires are heated to austenite transformation temperature, on the rotor critical speed is studied. In addition to these, the effect of variation of support stiffness due to activation of SMA in rotor supports is also studied. The objective of such a study is to estimate the amount of shape memory alloy in wires as well as in rotor supports, required to alter the rotor critical speed sufficiently enough (say by $30 \%$ ) in order to avoid resonance during rotor coast up/down. Results have been presented in terms of non-dimensional parameters and illustrated through numerical examples. Some issues associated with activation strategies to be adopted for such rotors during coast up/down have been discussed in a qualitative sense.

\section{THEORETICAL ANALYSIS}

Consider a flexibly supported composite rotor (Fig. 1) embedded with shape memory wires and carrying discs in the form of lumped masses. The

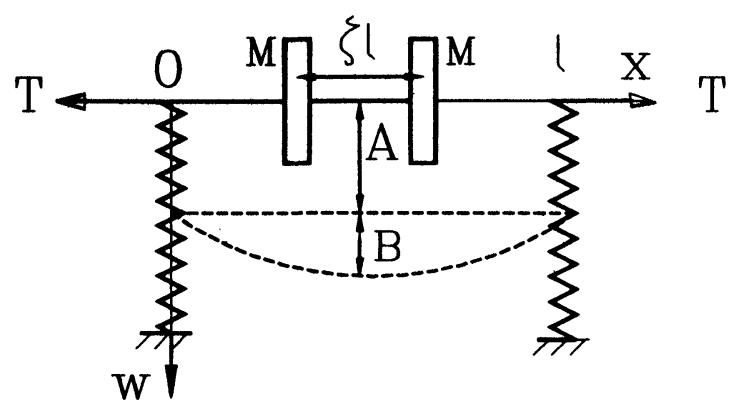

FIGURE 1 A two-mass rotor.

strain and kinetic energies, $U$ and $V$, respectively, are given by

$$
\begin{aligned}
U= & \frac{1}{2} \int_{0}^{1} E_{\mathrm{c}} I_{\mathrm{c}} w_{, x x}^{2} \mathrm{~d} x+\frac{1}{2} \int_{0}^{1} E_{\mathrm{n}} I_{\mathrm{n}} W_{, x x}^{2} \mathrm{~d} x \\
& +\frac{T}{2} \int_{0}^{1} w_{, x}^{2} \mathrm{~d} x+K w^{2}, \\
V & =\frac{1}{2} \int_{0}^{1} m(x) w_{, t}^{2} \mathrm{~d} x+\frac{1}{2} \sum M_{i} w_{, t}^{2} .
\end{aligned}
$$

For estimation of natural frequency, the shaft deflection can be assumed to be harmonic, i.e., $w(x, t)=W(x) \cos p t$. On substituting in Eqs. (1) and (2) and following Rayleigh's method (Rao and Gupta, 1984), the time dependence cancels out and the frequency equation is obtained.

A two-mass rotor with flexible isotropic supports as shown in Fig. 1 is considered. The two masses are identical and mounted symmetrical about the midspan. From the static deflection of the system, the following mode shape is assumed:

$$
\begin{aligned}
W(x) & =A+B \sin \frac{\pi x}{l}, \\
A & =\frac{2 M+m}{2 k}, \\
B & =\frac{l^{3}}{24 E I} \frac{\left[(1-\zeta)\left(1+\zeta-\zeta^{2} / 2\right) M+\frac{5}{16} m\right]}{\left(1+r_{t} / \pi^{2}\right)} .
\end{aligned}
$$

In Eq. (3), $m$ is mass of the shaft and $E I=E_{\mathrm{c}} I_{\mathrm{c}}+$ $E_{\mathrm{n}} I_{\mathrm{n}}$. From Rayleigh's method, the following 
frequency equation in terms of the non-dimensional parameters is obtained:

$$
\begin{aligned}
\frac{p^{2}}{p_{\mathrm{ss}}^{2}}= & \left(\left(1+r_{t} / \pi^{2}\right)\left(1+16 f_{\zeta} r_{m} / 5\right)^{2}\right. \\
& \left.+(3072 / 25) \pi^{4} r_{k}\left(1+2 r_{m}\right)^{2}\left(1+r_{t} / \pi^{2}\right)^{2}\right) \\
& /\left(\left(1+4 f_{\zeta 1} r_{m}\right)\left(1+16 f_{\zeta} r_{m} / 5\right)^{2}\right. \\
& +(32 / 25) r_{k}^{2}\left(1+2 r_{m}\right)^{3}\left(1+r_{t} / \pi^{2}\right)^{2}+(32 / 5 \pi) r_{k} \\
& \times\left(1+\pi f_{\zeta 2} r_{m}\right)\left(1+16 f_{\zeta} r_{m} / 5\right)\left(1+2 r_{m}\right) \\
& \left.\times\left(1+r_{t} / \pi^{2}\right)\right)
\end{aligned}
$$

where

$$
\begin{aligned}
p_{\mathrm{ss}}^{2} & =\frac{\pi^{4} E I}{m l^{4}}, \quad f_{\zeta}=(1-\zeta)\left(1+\zeta-\frac{\zeta^{2}}{2}\right), \\
f_{\zeta 1} & =\frac{1}{2}\left[\sin ^{2}\left(\frac{1-\zeta}{2}\right) \pi+\sin ^{2}\left(\frac{1+\zeta}{2}\right) \pi\right], \\
f_{\zeta 2} & =\frac{1}{2}\left[\sin \left(\frac{1-\zeta}{2}\right) \pi+\sin \left(\frac{1+\zeta}{2}\right) \pi\right], \\
r_{t} & =\frac{T}{E I / l^{2}}, \quad r_{k}=\frac{K_{\mathrm{s}}}{K}, \quad r_{m}=\frac{M}{m}, \quad K_{\mathrm{s}}=\frac{48 E I}{\beta} .
\end{aligned}
$$

It can be seen that natural frequencies for various special cases can be obtained from expression (4). If $\zeta$ is set to zero, we get the expression for a Jeffcott rotor with flexible supports and lumped mass $2 M$ at the midspan. In addition, if $r_{k}=0$, the expression for Jeffcott rotor on simple supports is obtained. If $r_{m}$ and $r_{t}$ are also set zero, then the RHS of expression (4) reduces to unity.

To estimate the effective longitudinal modulus, consider the cross-section of the shaft (Fig. 2). Here $d_{\mathrm{h}}$ and $d_{\mathrm{w}}$ are the diameters of the rubber sleeve and the SMA wires respectively. The stiffness of the rubber sleeve is ignored in the present analysis. The volume fraction of wires $V_{\mathrm{n}}$ and that of rubber $V_{\mathrm{r}}$, the shaft mass per unit length $m$ and equivalent longitudinal modulus $E$ are given by

$$
\begin{aligned}
& V_{\mathrm{n}}=\frac{n r_{d_{\mathrm{w}}}^{2}}{r_{d}^{2}-1}, \quad V_{\mathrm{r}}=\frac{n r_{d_{\mathrm{w}}}^{2}\left(r_{\mathrm{hn}}-1\right)}{r_{d}^{2}-1}, \\
& \frac{m}{m_{\mathrm{c}}}=1+\left(\frac{\rho_{\mathrm{n}}}{\rho_{\mathrm{c}}}-1\right) V_{\mathrm{n}}+\left(\frac{\rho_{\mathrm{r}}}{\rho_{\mathrm{c}}}-1\right) V_{\mathrm{r}},
\end{aligned}
$$

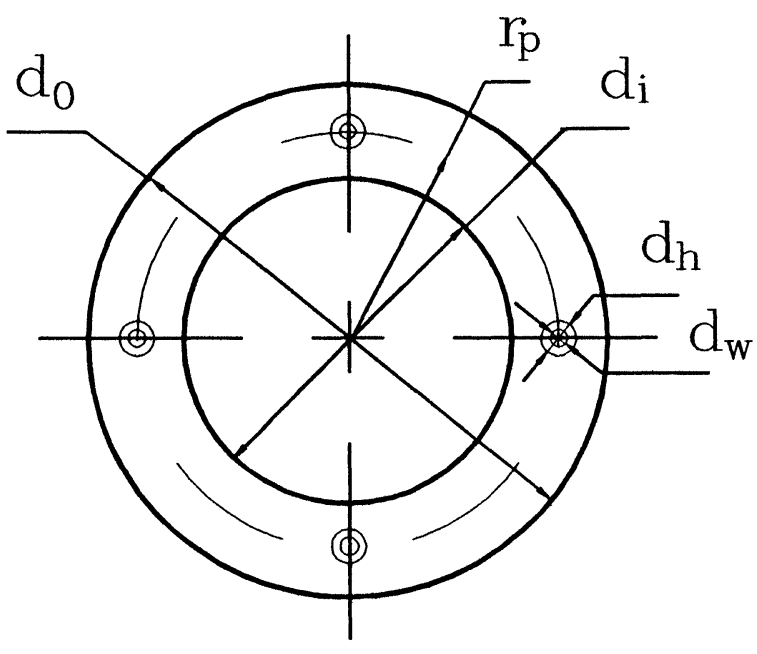

FIGURE 2 Rotor cross-section

$$
\begin{aligned}
\frac{E}{E_{\mathrm{c}}} & =1+\left(r_{E}-r_{\mathrm{hn}}\right) \frac{V_{\mathrm{n}}}{\left(1+r_{d}^{2}\right)}\left[\frac{r_{d}^{2}-1}{n} V_{\mathrm{n}}+\frac{\left(1+r_{d}^{2}\right)}{2}\right] \\
& \cong 1+\left(r_{E}-r_{\mathrm{hn}}\right) V_{\mathrm{n}} .
\end{aligned}
$$

The simplification above in expression (8) is possible since for thin walled shafts, $r_{d} \simeq 1$. In Eq. (7), $\rho$ represents the mass density. Also $m_{\mathrm{c}}$ and $E_{\mathrm{c}}$ refer to a composite shaft without SMA wires. The expressions for $m_{\mathrm{c}}$ and the various nondimensional parameters in Eqs. (6)-(8) are

$$
m_{\mathrm{c}}=\frac{\pi}{4}\left(d_{\mathrm{o}}^{2}-d_{\mathrm{i}}^{2}\right) \rho_{\mathrm{c}},
$$

$$
\begin{aligned}
& r_{E}=\frac{E_{\mathrm{n}}}{E_{\mathrm{c}}}, \quad r_{\mathrm{hn}}=\frac{I_{\mathrm{n}}}{I_{\mathrm{h}}}=\frac{d_{\mathrm{h}}^{2}}{d_{\mathrm{w}}^{2}}, \\
& r_{d}=\frac{d_{\mathrm{o}}}{d_{\mathrm{i}}}, \quad r_{\rho}=\frac{\rho_{n}}{\rho_{c}}, \quad r_{d_{\mathrm{w}}}=d_{\mathrm{w}} / d_{\mathrm{i}} .
\end{aligned}
$$

The longitudinal equivalent modulus of the fibre reinforced composite shaft is given by Tsai and Hahn (1980):

$$
E_{\mathrm{c}}=\frac{4\left(U_{1}-U_{5}\right)\left(U_{5}+\gamma U_{3}\right)-\beta^{2} U_{2}^{2}}{U_{1}-\beta U_{2}+\gamma U_{3}}
$$


where

$$
\gamma=\sum_{i=1}^{N} \frac{t_{i}}{t} \cos 4 \theta_{i}, \quad \beta=\sum_{i=1}^{N} \frac{t_{i}}{t} \cos 2 \theta_{i} .
$$

Here $t$ is the total thickness of the laminate equal to $\left(d_{\mathrm{o}}-d_{\mathrm{i}}\right) / 2$ in the present case and $t_{\mathrm{i}}$ and $\theta_{i}$ are the thickness and the fibre angle of the $i$ th lamina, $N$ being the total number of laminae. The laminate variants $U_{1}$ to $U_{5}$ are given by

$$
\begin{aligned}
U_{1} & =\frac{1}{8}\left(3 Q_{x x}+3 Q_{y y}+2 Q_{x y}+4 Q_{\mathrm{ss}}\right), \\
U_{2} & =\frac{1}{2}\left(Q_{x x}-Q_{y y}\right), \\
U_{3,5} & =\frac{1}{8}\left(Q_{x x}+Q_{y y}+2 Q_{x y} \mp 4 Q_{\mathrm{ss}}\right), \\
U_{4} & =\frac{1}{8}\left(Q_{x x}+Q_{y y}-Q_{x y}+4 Q_{\mathrm{ss}}\right),
\end{aligned}
$$

where

$$
\begin{aligned}
& Q_{x x}=\frac{E_{x}}{\left(1-\mu_{x}^{2} E_{y} / E_{x}\right)}, \quad Q_{y y}=\frac{E_{y}}{\left(1-\mu_{x}^{2} E_{y} / E_{x}\right)}, \\
& Q_{x y}=\mu_{x} Q_{y y}, \quad Q_{\mathrm{ss}}=E_{\mathrm{s}} .
\end{aligned}
$$

The longitudinal modulii $E_{x}, E_{y}$, the shear modulus $E_{\mathrm{s}}$ and the longitudinal Poisson's ratio $\mu_{x}$, with respect to the principal material axes of symmetry, $x$ and $y$ (Fig. 3), are functions of the individual properties and the volume fractions of

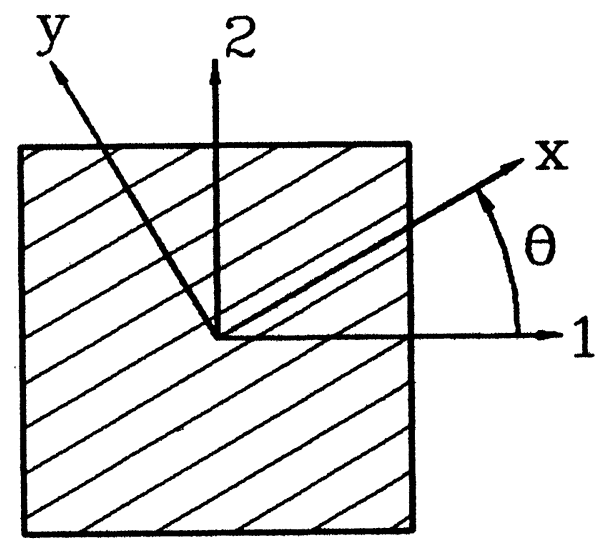

FIGURE 3 Composite laminate. the fibre and the matrix.

$$
\begin{aligned}
& E_{x}=E_{\mathrm{f}} V_{\mathrm{f}}+E_{\mathrm{m}} V_{\mathrm{m}}, \quad E_{y}=\frac{E_{\mathrm{m}}}{\left(V_{\mathrm{m}}+V_{\mathrm{f}} E_{\mathrm{m}} / E_{\mathrm{f}}\right)}, \\
& E_{\mathrm{s}}=\frac{G_{\mathrm{m}}}{\left(V_{\mathrm{m}}+V_{\mathrm{f}} G_{\mathrm{m}} / G_{\mathrm{f}}\right)}, \quad \mu_{x}=\mu_{\mathrm{m}} V_{\mathrm{m}}+\mu_{\mathrm{f}} V_{\mathrm{f}} .
\end{aligned}
$$

In the above, subscripts $m$ and $f$ denote the matrix and the fibre, respectively.

The fundamental natural frequency of the composite rotor embedded with SMA wires can be determined by successive use of expressions (15) in (4). It may be noted that since the gyroscopic effects are not taken into account and support stiffness $K$ is assumed to be independent of rotor speed, the natural frequency from expression (4) will give the first rotor critical speed.

\section{NUMERICAL EXAMPLES}

Figure 4 gives the equivalent longitudinal modulus of composite shaft as obtained from Eqs. (11)-(15) for three types of composites boron/epoxy, carbon/ epoxy and glass/epoxy. The curves with solid lines represent single ply configuration with fibre angle denoted on $x$-axis. The curves with dotted lines denote a symmetric configuration $\left(\theta, 45^{\circ}, 45^{\circ}, \theta\right)$ with four layers $(N=4)$ of equal thickness and $\theta$ varying from 0 to $45^{\circ}$. Following typical material properties from literature (Jones, 1975) are

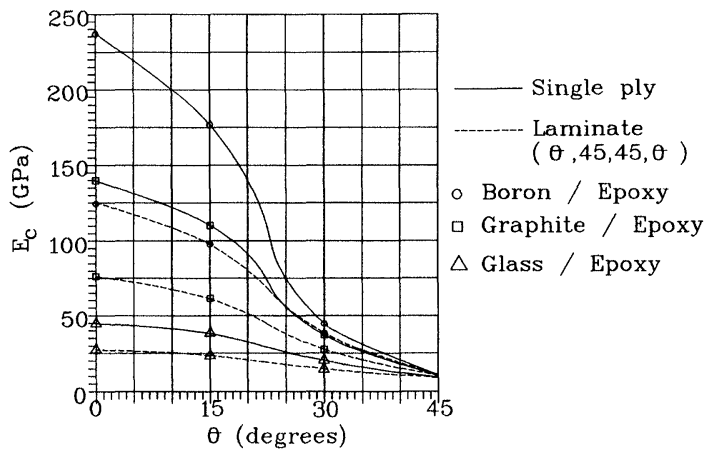

FIGURE 4 Equivalent modulus of composite laminate. 
assumed: The value of Young's modulus $E$ for glass, carbon, boron and epoxy is taken, respectively, as 72.4, 231, 393 and $3 \mathrm{GPa}$. Poisson's ratio for glass, carbon and boron is assumed to be 0.2 and for epoxy as 0.3 . The shear modulus is given by $G=(E / 2)(1+\mu)$. Assuming fibre and matrix volume fractions of 0.6 and 0.4 , we get from expression (15) for glass/epoxy, carbon/epoxy and boron/epoxy, respectively, the value of $E_{x}$ as 44.64 , 140 and $237 \mathrm{GPa}$, the value of $E_{y}$ as $7.06,7.35$ and $7.42 \mathrm{GPa}$, and value of $E_{\mathrm{s}}$ as $2.73,2.83$ and $2.85 \mathrm{GPa}$. The Poisson's ratio $\mu_{x}$ for all the three composites works out to 0.24 .

Figure 5 is a graphical representation of Eq. (8), which is a linear relation between $E / E_{\mathrm{c}}$ and $r_{E}=E_{\mathrm{n}} /$ $E_{\mathrm{c}}$. In Fig. 5, plots are given for two values of $r_{\mathrm{hn}}=1$ and 4 and four values of NITINOL volume fraction $V_{\mathrm{n}}=2 \%, 5 \%, 10 \%$ and $20 \%$. The $E / E_{\mathrm{c}}$ ratio increases with increasing value of $r_{E}$ and $V_{\mathrm{n}}$. The value of $E / E_{\mathrm{c}}$ is also quite sensitive to the nondimensional ratio $r_{\mathrm{hn}}$.

From Fig. 4 it is noticed that the value of $E_{\mathrm{c}}$ could vary in a wide range from about 10 to $237 \mathrm{GPa}$. The value of $E_{\mathrm{n}}$ could vary typically (Rogers, 1990), from about $25 \mathrm{GPa}$ in the unactivated martensitic phase (below the martensitic transformation temperature) to about $90 \mathrm{GPa}$ in the activated austenite phase (above the austenite transformation temperature). Thus the range of $r_{E}$ is from

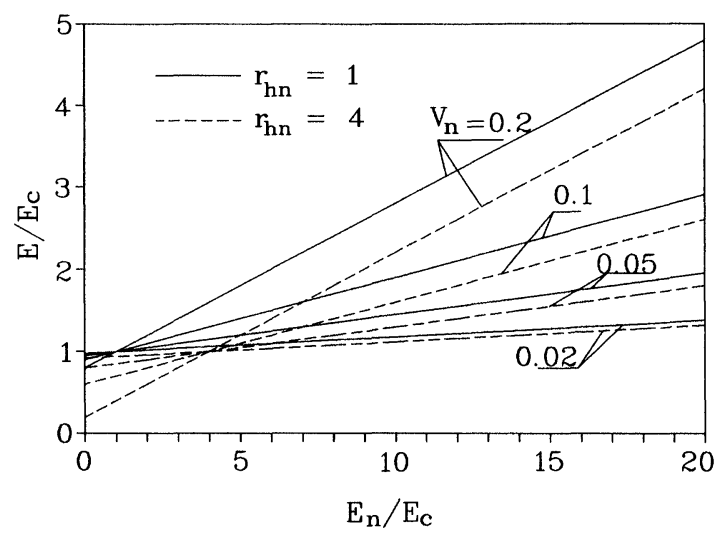

FIGURE 5 Equivalent longitudinal modulus of composite shaft with SMA fibres.
$25 / 237=0.1$ to $90 / 10=9$. For fibre angles greater than $45^{\circ}$, value of $E_{\mathrm{c}}$ could be much smaller resulting in an upper value of $r_{E}$ much greater than 9 .

The variation of natural frequency (Eq. (4)) with various nondimensional parameters $r_{t}, r_{k}$ and $r_{m}$ is given in Fig. 6(a) and (b) for two values of $\zeta=0$ and 0.5 , respectively. The effect of $r_{m}$ and $r_{k}$ is obvious. The natural frequency decreases as the mass ratio $r_{\mathrm{m}}$ is increased. Same trend is observed when $r_{k}=K_{\mathrm{s}} / K$ is increased, i.e., the supports are made flexible.

In order to assess the effect of NITINOL wires on the natural frequency, it is necessary to consider two effects: (i) variation in the value of $E_{\mathrm{n}}$ from about $25 \mathrm{GPa}$ in unactivated state to about $90 \mathrm{GPa}$ in activated state as the temperature is increased from below the martensitic transformation temperature to one above the austenite transformation temperature; (ii) development of large phase recovery forces in the wires when these are activated. The first effect is taken into account through Fig. 5, from which the equivalent longitudinal modulus $E$ of the shaft is obtained. The second effect manifests itself through the nondimensional parameter $r_{t}$ in the term $\left(1-r_{t} / \pi^{2}\right)$ in the frequency equation (4). If the wires are imparted an initial strain and are suitably restrained, then large phase recovery tensile force $T$ will develop due to shape memory effect when the wires are activated by increasing their temperature above the austenite transformation temperature. The phase recovery stresses (Rogers, 1990) can be as high as about $500 \mathrm{MPa}$. It should be noted that the value of $r_{t}$ could vary over a large range depending on relative values of $E, l, d_{\mathrm{o}}, d_{\mathrm{i}}, V_{\mathrm{n}}$ and $T$. Also for small values of $r_{k}$ (flexible shaft and rigid support), the effect of $r_{t}$ is more dominant because the shaft being flexible undergoes appreciable flexure. On the other hand, for large values of $r_{k}$ (rigid shaft and flexible support), the flexure in the shaft is negligible and the effect of $r_{t}$ is small (see Eq. (1)).

Let us now consider a specific case with following geometrical data, $d_{\mathrm{o}}=50 \mathrm{~mm}, d_{\mathrm{i}}=40 \mathrm{~mm}$, $d_{\mathrm{w}}=1 \mathrm{~mm}, d_{\mathrm{h}}=2 \mathrm{~mm}, l=1 \mathrm{~m}$. Let the shaft material be carbon/epoxy with single ply configuration, 


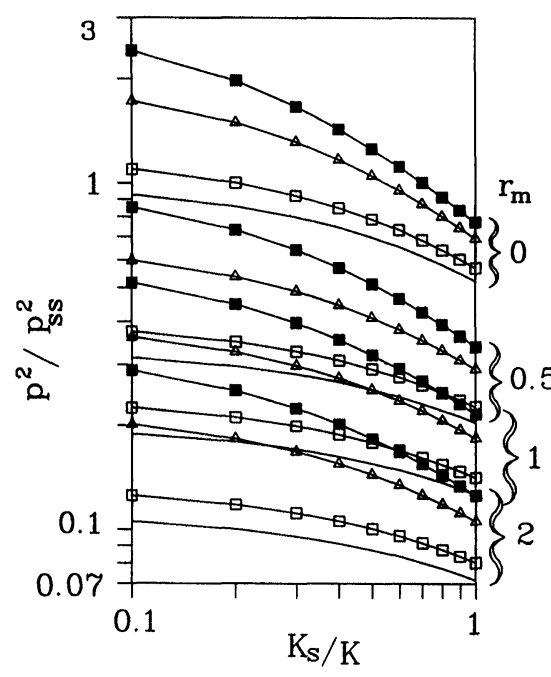

(a)

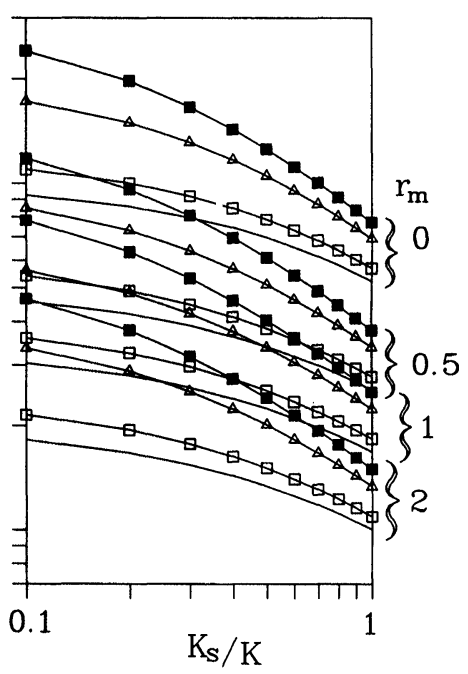

(b)

FIGURE 6 Variation of shaft natural frequency with various parameters (a) $\zeta=0$, (b) $\zeta=0.5 ;(-) r_{\mathrm{t}}=0$; (- $\square-\mathrm{r}_{\mathrm{t}}=0.02$; $(-\boldsymbol{\square}-) r_{\mathrm{t}}=0.2 ;(-\boldsymbol{\Delta}-) r_{\mathrm{t}}=0.1$.

fibre angle equal to $30^{\circ}$ and fibre volume fraction of 0.6 . The number of wires be $N=18$. Let the value of $E_{\mathrm{n}}$ be 25 and $90 \mathrm{GPa}$, respectively, in unactivated martensitic and activated austenite phases.

From Fig. $4, E_{\mathrm{c}} \approx 37 \mathrm{GPa}$. The volume fraction (Eq. (6)) for wires is $V_{\mathrm{n}}=0.02(2 \%)$. The values of $r_{E}$ for the unactivated and the activated states of the wires are 0.676 and 2.43, respectively. The nondimensinal ratio $r_{\mathrm{hn}}=4$. From Fig. 5 the values of $E / E_{\mathrm{c}}$ for these two cases is 0.9335 and 0.969 . It is obvious that due to small volume fraction $V_{\mathrm{n}}$ of wires, the effect of these on equivalent stiffness $E$ is negligible. Also because $r_{\mathrm{hn}}>r_{E}$, there is a net reduction in the value of equivalent stiffness. This reduction will be more if $V_{\mathrm{n}}$ is increased. For example if $V_{\mathrm{n}}=20 \%$ the values of $E / E_{\mathrm{c}}$ for the two cases will be 0.3346 and 0.686 , respectively.

Thus we observe that placing the SMA wires in rubber sleeves is quite detrimental to the shaft stiffness, because of the relatively larger volume occupied by the rubber. In the above example, the volume fraction of rubber sleeves $V_{\mathrm{r}}$ in the composite shaft will be three times that of $V_{\mathrm{n}}$. Thus when $V_{\mathrm{n}}=2 \%$, then $V_{\mathrm{r}}=6 \%$ and the volume fraction for the composite $V_{\mathrm{c}}=92 \%$. If $V_{\mathrm{n}}=$ $20 \%$, then $V_{\mathrm{r}}=60 \%$ and $V_{\mathrm{c}}=20 \%$, which obviously is not a desirable proportion. Therefore, when the shaft stiffness is an important consideration requiring larger values of $V_{\mathrm{n}}$, the rubber sleeve dimensions must be either reduced drastically or the rubber sleeves should be eliminated altogether. If rubber sleeves are not used $\left(r_{\mathrm{hn}}=1\right)$, the values of $E$ / $E_{\mathrm{c}}$ for two cases (unactivated and activated wires) as shown in Table I are 0.9935 and 1.0286 for $V_{\mathrm{n}}=2 \%, 0.9676$ and 1.143 for $V_{\mathrm{n}}=10 \%$ and 0.9352 and 1.286 for $V_{\mathrm{n}}=20 \%$. The aspects of fabrication of shafts with or without the rubber sleeves are beyond the scope of the present paper.

For simplicity let us first consider the case of rigid supports $r_{k}=0$ and a Jeffcott rotor with mass $2 M$ at midspan i.e., $\zeta=0$. Assuming further a value of $r_{m}=1$, the frequency equation (4) reduces to

$$
p^{2}=0.2 p_{\mathrm{ss}}^{2}\left(1+r_{t} / \pi^{2}\right)
$$

The value of $I$ for the shaft is $\pi \cdot\left(50^{4}-40^{4}\right) \cdot 10^{-12} /$ $64=0.1811 \cdot 10^{-6} \mathrm{~m}^{4}$. For the shaft without SMA wires, $E I=37 \cdot 10^{9} \cdot 0.1811 \cdot 10^{-6}=6701 \mathrm{~N} \mathrm{~m}^{2}$ and 
TABLE I Frequencies of Jeffcott rotor on simple supports without wire tension $(T=0)$

\begin{tabular}{|c|c|c|c|c|c|c|c|c|}
\hline$V_{\mathrm{n}} \%$ & $r_{\mathrm{hn}}$ & $\mathrm{u} / \mathrm{a}$ & $E / E_{\mathrm{c}}$ & $E(\mathrm{GPa})$ & $m(\mathrm{~kg} / \mathrm{m})$ & $E m_{\mathrm{c}} / E_{\mathrm{c}} m$ & $p_{\mathrm{ss}}(\mathrm{rad} / \mathrm{s})$ & $p_{\mathrm{ssm}}(\mathrm{rad} / \mathrm{s})$ \\
\hline \multirow[t]{2}{*}{2} & 1 & $\mathrm{u}$ & 0.9935 & 36.76 & 1.199 & 0.937 & 735.52 & 328.89 \\
\hline & & a & 1.0286 & 38.06 & 1.199 & 0.97 & 748.31 & 334.65 \\
\hline \multirow[t]{2}{*}{2} & 4 & $\mathrm{u}$ & 0.9335 & 34.54 & 1.182 & 0.893 & 717.98 & 321.09 \\
\hline & & $\mathrm{a}$ & 0.969 & 35.85 & 1.182 & 0.927 & 731.46 & 327.12 \\
\hline \multirow[t]{2}{*}{10} & 1 & $\mathrm{u}$ & 0.9676 & 35.8 & 1.470 & 0.744 & 655.45 & 293.13 \\
\hline & & $\mathrm{a}$ & 1.143 & 42.29 & 1.470 & 0.879 & 712.39 & 318.59 \\
\hline \multirow[t]{2}{*}{10} & 4 & $\mathrm{u}$ & 0.6676 & 24.7 & 1.385 & 0.545 & 560.89 & 250.84 \\
\hline & & $\mathrm{a}$ & 0.843 & 31.19 & 1.385 & 0.688 & 630.29 & 281.87 \\
\hline \multirow[t]{2}{*}{20} & 1 & $\mathrm{u}$ & 0.9352 & 34.6 & 1.810 & 0.584 & 580.71 & 259.7 \\
\hline & & $\mathrm{a}$ & 1.286 & 47.58 & 1.810 & 0.804 & 680.97 & 304.54 \\
\hline \multirow[t]{2}{*}{20} & 4 & $\mathrm{u}$ & 0.3346 & 12.38 & 1.640 & 0.231 & 364.92 & 163.2 \\
\hline & & $\mathrm{a}$ & 0.686 & 25.38 & 1.640 & 0.473 & 522.49 & 233.66 \\
\hline
\end{tabular}

$\mathrm{u}$ - unactivated; a - activated.

assuming mass density of $1600 \mathrm{~kg} / \mathrm{m}^{3}$ for carbon composite, $m=1.131 \mathrm{~kg} / \mathrm{m}$. The natural frequency of composite shaft is $p_{\mathrm{ss}}=\pi^{2} \cdot(6701 / 1.131)^{0.5}=$ $759.7 \mathrm{rad} / \mathrm{s}(7254.5 \mathrm{rpm})$ and that with lumped mass (Eq. (16)) is $p_{\text {ssm }}=0.2^{1 / 2} \cdot 759.7=339.75 \mathrm{rad} / \mathrm{s}$.

\section{Effect of Stiffness Variation of Wires}

Next, consider the shaft with NITINOL wires in rubber sleeves with $V_{\mathrm{n}}=2 \%$, but without any tensile force i.e., $r_{t}=0$. For $r_{\mathrm{hn}}=4, E$ is 34.54 and $35.85 \mathrm{GPa}$ for unactivated and activated wires, respectively. Assuming mass density $\rho$ of composite, NITINOL and rubber to be 1600,6400 and $1200 \mathrm{~kg} / \mathrm{m}^{3}$, respectively, the value of $m$ from Eq. (7) works out to 1.182 . The rotor natural frequencies for the unactivated and activated wires become 321.09 and $327.12 \mathrm{rad} / \mathrm{s}$, respectively. It is obvious that the variation in natural frequency of about $1.88 \%$ from 321.09 to $327.12 \mathrm{rad} / \mathrm{s}$ is not adequate to avoid resonance in rotor coast up/down. If we increase the NITINOL volume fraction to $20 \%$ $\left(V_{\mathrm{n}}=0.2\right)$, keeping all other factors same as before, the two natural frequencies work out to 163.2 and $233.66 \mathrm{rad} / \mathrm{s}$. This variation of natural frequencies between the unactivated and activated wires is about $43 \%$, which will be quite adequate for a resonant free coast up/down operation. However, it is at the expense of shaft stiffness and results in decrease of rotor critical speed. For $V_{\mathrm{n}}=10 \%$, these values are 250.84 and $281.87 \mathrm{rad} / \mathrm{s}$ for unactivated and activated wires giving a $12.4 \%$ variation. These calculations are summarised in Table I.

If rubber sleeves are eliminated altogether $\left(r_{\mathrm{hn}}=\right.$ $1)$, the rotor natural frequencies with unactivated and activated wires are 328.89 and $334.65 \mathrm{rad} / \mathrm{s}$ for $V_{\mathrm{n}}=2 \%$, and 293.13 and $318.59 \mathrm{rad} / \mathrm{s}$ for $V_{\mathrm{n}}=10 \%$, and 259.7 and $304.54 \mathrm{rad} / \mathrm{s}$ for $V_{\mathrm{n}}=$ $20 \%$. Percentage variation in natural frequencies from unactivated to activated wires is $1.75 \%$, $8.69 \%$ and $17.27 \%$ for $V_{\mathrm{n}}$ equal to $2 \%, 10 \%$ and $20 \%$, respectively.

\section{Combined Effect of Stiffness Variation and Wire Tension}

Let us assume that the phase recovery stress in the wires is of the order of about $250 \mathrm{MPa}$, which corresponds to about 3\% initial strain (Rogers, 1990). The total tensile force in all the wires will be $T=(\pi / 4) \cdot\left(50^{2}-40^{2}\right) \cdot 10^{-6} \cdot 250 \cdot 10^{6} \cdot V_{\mathrm{n}}$, which is (see Table II) $3.534,17.617$ and $35.34 \mathrm{kN}$ for $V_{\mathrm{n}}$ equal to $2 \%, 10 \%$ and $20 \%$, respectively. The value of $r_{t}=T /\left(E I / l^{2}\right)$ for various cases is given in column 4 of Table II. The effect of tension in wires on rotor natural frequency is evident in Table II. Column 6 gives the percentage increase in rotor natural frequency due to tension in wires alone. The value of natural frequency of rotor with wires activated and effect of tension in wires accounted for, is given 
TABLE II Effect of wire tension on natural frequencies of simply supported Jeffcott rotor

\begin{tabular}{cccccccc}
\hline$V_{\mathrm{n}} \%$ & $r_{\mathrm{hn}}$ & $T(\mathrm{kN})$ & $r_{\mathrm{t}}$ & $\left(1+r_{t} / \pi^{2}\right)^{1 / 2}$ & Percentage variation due to $r_{\mathrm{t}}$ & $p(\mathrm{rad} / \mathrm{s})$ & Percentage variation \\
\hline 2 & 1 & 3.534 & 0.5127 & 1.0256 & 2.56 & 343.22 & 4.36 \\
2 & 4 & 3.534 & 0.5444 & 1.0272 & 2.72 & 336.02 & 4.65 \\
10 & 1 & 17.671 & 2.3064 & 1.1110 & 11.10 & 353.95 & 20.75 \\
10 & 4 & 17.671 & 3.1270 & 1.1479 & 14.79 & 323.56 & 28.99 \\
20 & 1 & 35.343 & 4.0992 & 1.1902 & 19.02 & 362.46 & 39.57 \\
20 & 4 & 35.343 & 7.6820 & 1.3345 & 33.45 & 311.82 & 91.07 \\
\hline
\end{tabular}

for various cases in column 7. The net percentage increase in rotor natural frequency compared to the case of unactivated wires (column 9 of Table I) is given in last column of Table II. It is to be noted that the percentage increase $(20.1 \%$ to $91 \%)$ for $V_{\mathrm{n}}=$ $10 \%$ and $20 \%$ is quite substantial and adequate for a safe rotor coast up/down.

Comparison of results of last columns of Tables I and II clearly shows the dominant effect of tension in wires on rotor natural frequency. For example, for the case of $V_{\mathrm{n}}=20 \%$ and $r_{\mathrm{hn}}=1$, the percentage increase in natural frequency rises from $17.27 \%$ to $39.57 \%$ when the effect of tension in wires is accounted for. Results for $V_{\mathrm{n}}=20 \%$ also show that tension in wires offsets considerably the loss of bending rigidity of the shaft. For example, the rotor natural frequency increases from 304.54 to $362.46 \mathrm{rad} / \mathrm{s}$ (19.2\% increase) for $r_{\mathrm{hn}}=1$ and from 233.66 to $311.82 \mathrm{rad} / \mathrm{s} \quad(33.45 \%$ increase $)$ for $r_{\mathrm{hn}}=4$.

\section{Combined Effects of Wire Stiffness, Wire Tension and Support Stiffness}

Shape memory alloy can also be used in the rotor support system (Nagaya et al., 1987). Liang and Rogers (1993) have discussed the variation of stiffness of springs made of the shape memory material. It is shown that the stiffness of the springs, which is proportional to Young's modulus of the material, could be made to vary 3-4 times by activating the shape memory material. It will be desirable to control the rotor support stiffness by using the shape memory material in addition to the control of rotor shaft stiffness by varying the wire

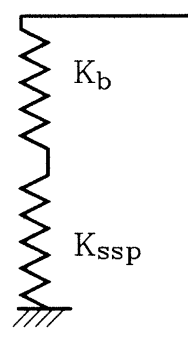

(a)

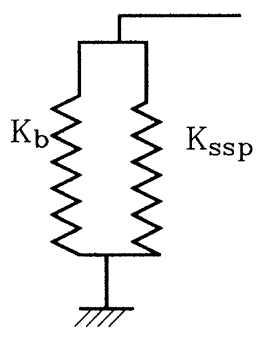

(b)
FIGURE 7 Support stiffness arrangement (a) series, (b) parallel.

Young's modulus and the tension (shape memory effect). The combination of all the three factors will provide maximum flexibility to the designer to alter rotor critical speeds in a wide range.

For the case of flexible supports, two configurations as shown in Fig. 7 can be considered. Here $K_{\mathrm{b}}$ represents the stiffness of the pedestals or/and that provided by fluid film or rolling element bearings. $K_{\text {ssp }}$ represents the stiffness of the spring made of the shape memory material which can be placed either in series (configuration I) or in parallel (configuration II). The effective support stiffness is $K=K_{\mathrm{b}} \cdot K_{\mathrm{ssp}} /\left(K_{\mathrm{b}}+K_{\mathrm{ssp}}\right)$ and $\left(K_{\mathrm{b}}+K_{\text {ssp }}\right)$ for configurations I and II, respectively. It is obvious that for $K_{\text {ssp }}$ to have appreciable effect, $K_{\mathrm{b}}$ should be sufficiently rigid in configuration I and should be sufficiently flexible in configuration II. The choice of configuration I or II therefore will depend on the relative value of $K_{\mathrm{b}}$. Thus, configuration I will be desirable when $K_{\mathrm{b}} \gg K_{\text {ssp }}$ while configuration II is desirable when $K_{\mathrm{b}} \ll K_{\text {ssp. }}$. 
TABLE III Natural frequency of a Jeffcott rotor on flexible supports

\begin{tabular}{lcccccccccc}
\hline$V_{\mathrm{n}}(\%)$ & $r_{\mathrm{hn}}$ & $p_{1}$ & $p_{2}$ & $p_{3}$ & $p_{4}$ & $p_{5}$ & $\%(1-2)$ & $\%(1-3)$ & $\%(1-4)$ & $\%(1-5)$ \\
\hline 2 & 1 & 262.0 & 269.0 & 301.7 & 306.1 & 312.6 & 2.7 & 15.2 & 16.8 & 19.3 \\
2 & 4 & 258.7 & 266.2 & 296.0 & 300.6 & 307.5 & 2.9 & 14.4 & 16.2 & 18.9 \\
10 & 1 & 234.6 & 262.1 & 269.4 & 288.8 & 314.1 & 11.7 & 14.8 & 23.1 & 33.9 \\
10 & 4 & 213.2 & 252.2 & 236.3 & 261.7 & 293.9 & 18.3 & 10.9 & 22.8 & 37.9 \\
20 & 1 & 209.2 & 252.0 & 239.4 & 273.0 & 312.1 & 20.5 & 14.4 & 30.5 & 49.2 \\
20 & 4 & 149.7 & 238.3 & 158.4 & 219.9 & 280.8 & 59.2 & 5.8 & 46.9 & 87.6 \\
\hline
\end{tabular}

TABLE IV Natural frequency of two-mass rotor on flexible supports

\begin{tabular}{lcccccccccc}
\hline$V_{\mathrm{n}}(\%)$ & $r_{\mathrm{hn}}$ & $p_{1}$ & $p_{2}$ & $p_{3}$ & $p_{4}$ & $p_{5}$ & $\%(1-2)$ & $\%(1-3)$ & $\%(1-4)$ & $\%(1-5)$ \\
\hline 2 & 1 & 304.1 & 310.5 & 371.0 & 376.0 & 383.1 & 2.1 & 22.0 & 23.6 & 26.0 \\
2 & 4 & 301.5 & 308.4 & 364.9 & 370.1 & 377.7 & 2.3 & 21.0 & 22.8 & 25.3 \\
10 & 1 & 272.8 & 297.4 & 331.7 & 353.1 & 380.4 & 9.0 & 21.6 & 29.4 & 39.5 \\
10 & 4 & 253.4 & 290.6 & 294.7 & 323.9 & 359.8 & 14.7 & 16.3 & 27.8 & 42.0 \\
20 & 1 & 243.7 & 281.3 & 295.1 & 332.1 & 373.0 & 15.4 & 21.1 & 36.2 & 53.0 \\
20 & 4 & 184.0 & 273.0 & 200.8 & 274.0 & 342.4 & 48.4 & 9.1 & 48.9 & 86.1 \\
\hline
\end{tabular}

The frequency equation for the Jeffcott rotor on flexible supports is obtained from expression (4) by $\operatorname{setting} f_{\zeta}=f_{\zeta 1}=f_{\zeta 2}=1$ and $r_{m}=1$ :

$$
\begin{aligned}
\frac{p^{2}}{p_{\mathrm{ss}}^{2}}= & \left(17.6\left(1+r_{t} / \pi^{2}\right)+11.3543 r_{k}\left(1+r_{t} \pi^{2}\right)^{2}\right) \\
& /\left(88.2+106.3085 r_{k}\left(1+r_{t} / \pi^{2}\right)\right. \\
& \left.+34.56 r_{k}^{2}\left(1+r_{t} / \pi^{2}\right)^{2}\right) .
\end{aligned}
$$

If $V_{\mathrm{n}}=0$, then $E=E_{\mathrm{c}}$ and $r_{t}=0$. Let us assume $r_{k}=1\left(K=K_{\mathrm{s}}\right)$ when the SMA in the rotor support system is unactivated. From Eq. (17), $p^{2} / p_{\mathrm{ss}}^{2}=$ 0.099 . Therefore $p=759.7 \cdot 0.099^{1 / 2}=239.03 \mathrm{rad} / \mathrm{s}$. If stiffness $K$ increases three times because of activation of SMA in rotor supports then, $r_{k}=1 / 3$. From Eq. (17), $p^{2} / p_{\mathrm{ss}}^{2}=0.1471$. The natural frequency becomes $p=759.7 \cdot 0.1471^{1 / 2}=291.37 \mathrm{rad} /$ $\mathrm{s}$. Thus by activating the SMA in the rotor support system alone, for the case under consideration $\left(V_{\mathrm{n}}=0\right)$, a percentage increase of (291.37$239.05) \cdot 100 / 239.05=21.9 \%$ is obtained.

Table III gives for the Jeffcott rotor $(\zeta=0)$, frequency for five cases ranging from one extreme $\left(p_{1}\right)$ condition when both the SMA in rotor support and the wires in rotor shaft are unactivated to the other extreme $\left(p_{5}\right)$ when both (the supports and the wires) are activated including the effect of tension in wires. The natural frequencies $p_{1}$ to $p_{5}$ in $\mathrm{rad} / \mathrm{s}$ given in Tables III-VI correspond to following five cases:

$p_{1}$ - SMA in rotor support and wires unactivated; $p_{2}$ - SMA in rotor support unactivated, wires in shaft activated; tension in wires present;

$p_{3}$ - SMA in rotor support activated, wires in shaft unactivated;

$p_{4}-\mathrm{SMA}$ in rotor support and shaft wires activated, tension in wires absent;

$p_{5}-\mathrm{SMA}$ in rotor supports and shaft wires activated, tension in wires present.

In the present analysis, the value of $K_{\text {ssp }}$ for the unactivated and the activated supports is assumed to be $48 E_{\mathrm{c}} I / l^{3}$ and $144 E_{\mathrm{c}} I / l^{3}$, respectively. Therefore the effective value of $r_{k}$ in Eq. (17) is $E / E_{\mathrm{c}}$ for the unactivated support and $E / 3 E_{\mathrm{c}}$ for the activated support. Results of Table III show that substantial percentage increase $\left(p_{5}-p_{1}\right) \cdot 100 / p_{1}$ in natural frequency is obtained. This value is $19 \%$ for $V_{\mathrm{n}}=2 \%$ and $34-38 \%$ for $V_{\mathrm{n}}=10 \%$ and about $50 \%$ for $V_{\mathrm{n}}=20 \%$. The combination of $V_{\mathrm{n}}=20 \%$ and $r_{\mathrm{hn}}=4$ can be ignored because $V_{\mathrm{c}}$ for this case is only $20 \%$. The values of $p_{2}$ and $p_{3}$ show that in 
TABLE V Natural frequency of Jeffcott rotor on flexible supports with loss of stiffness of composite accounted for

\begin{tabular}{ccccccccccc}
\hline$V_{\mathrm{n}}(\%)$ & $r_{\mathrm{hn}}$ & $p_{1}$ & $p_{2}$ & $p_{3}$ & $p_{4}$ & $p_{5}$ & $\%(1-2)$ & $\%(1-3)$ & $\%(1-4)$ & $\%(1-5)$ \\
\hline 2 & 1 & 262.0 & 219.3 & 301.7 & 230.8 & 240.8 & -16.3 & 15.2 & -11.9 & -8.1 \\
2 & 4 & 258.7 & 216.7 & 296.0 & 226.4 & 236.9 & -16.3 & 14.4 & -12.5 & -8.4 \\
10 & 1 & 234.6 & 234.1 & 269.4 & 233.3 & 268.6 & -0.2 & 14.8 & -0.6 & 14.5 \\
10 & 4 & 213.2 & 228.1 & 236.3 & 215.5 & 257.3 & 7.0 & 10.9 & 1.1 & 20.7 \\
20 & 1 & 209.2 & 236.7 & 239.4 & 234.0 & 284.0 & 13.1 & 14.4 & 11.9 & 35.7 \\
20 & 4 & 149.7 & 232.4 & 158.4 & 205.0 & 271.2 & 55.3 & 5.8 & 37.0 & 81.2 \\
\hline
\end{tabular}

TABLE VI Natural frequency of two-mass rotor on flexible supports with loss of stiffness of composite accounted for

\begin{tabular}{rcccccccrrr}
\hline$V_{\mathrm{n}}(\%)$ & $r_{\mathrm{hn}}$ & $p_{1}$ & $p_{2}$ & $p_{3}$ & $p_{4}$ & $p_{5}$ & $\%(1-2)$ & $\%(1-3)$ & $\%(1-4)$ & $\%(1-5)$ \\
\hline 2 & 1 & 304.1 & 262.5 & 371.0 & 289.5 & 301.3 & -13.7 & 22.0 & -4.8 & -0.9 \\
2 & 4 & 301.5 & 260.0 & 364.9 & 284.5 & 296.9 & -13.7 & 21.0 & -5.6 & -1.5 \\
10 & 1 & 272.8 & 272.3 & 331.7 & 290.6 & 330.7 & -0.2 & 21.6 & 6.5 & 21.3 \\
10 & 4 & 253.4 & 268.1 & 294.7 & 270.3 & 318.8 & 5.8 & 16.3 & 6.6 & 25.8 \\
20 & 1 & 243.7 & 268.5 & 295.1 & 289.0 & 343.8 & 10.1 & 21.1 & 18.6 & 41.0 \\
20 & 4 & 184.0 & 267.7 & 200.8 & 256.6 & 331.9 & 45.5 & 9.1 & 39.5 & 80.4 \\
\hline
\end{tabular}

general the percentage increase $\left(p_{2}-p_{1}\right) \cdot 100 / p_{1}$ in natural frequency, when only wires are activated, increases with increasing $V_{\mathrm{n}}$. For example it is $2.7 \%$ for $V_{\mathrm{n}}=2 \%$ and $20.5 \%$ for $V_{\mathrm{n}}=20 \%$, when $r_{\mathrm{hn}}=1$. Percentage increase $\left(p_{3}-p_{1}\right) \cdot 100 / p_{1}$ is around $15 \%$ for all values of $V_{\mathrm{n}}$ and $r_{\mathrm{hn}}$. The case of $V_{\mathrm{n}}=20 \%$ and $r_{\mathrm{hn}}=4$ is impracticable and hence ignored in further discussion. Comparison of results of last two columns of Table III clearly shows that the effect of tension in wires becomes more dominant as the value of $V_{\mathrm{n}}$ increases. For $r_{\mathrm{hn}}=1$, the percentage increase in the natural frequency due to this effect rises from 16.8 to 19.3 for $V_{\mathrm{n}}=2 \%$ and from 30.5 to 49.2 for $V_{\mathrm{n}}=20 \%$.

For the two-mass rotor $\zeta=0.5$. Substituting $\zeta=0.5$ and $r_{m}=1$ in Eq. (4), we get

$$
\begin{aligned}
\frac{p^{2}}{p_{\mathrm{ss}}^{2}}= & \left(10.24\left(1+r_{t} / \pi^{2}\right)+11.3543 r_{k}\left(1+r_{t} / \pi^{2}\right)^{2}\right) \\
& /\left(30.72+62.9951 r_{k}\left(1+r_{t} / \pi^{2}\right)\right. \\
& \left.+34.56 r_{k}^{2}\left(1+r_{t} / \pi^{2}\right)^{2}\right)
\end{aligned}
$$

Results from frequency equation (18) are given in Table IV. Comparison of results of Tables III and IV shows that the general trend of results remains the same when $\zeta=0.5$. The rotor natural frequency in all cases has increased because of splitting of the total mass $2 M$ in two lumped masses $M$ each at a distance of $\zeta l$. The relative (percentage) increase in rotor natural frequency for the various cases has also increased slightly in comparison to the case when $\zeta=0$. Therefore a Jeffcott model can be used as a first approximation of a multimass rotor system on flexible supports to assess the volume fraction of SMA $\left(V_{\mathrm{n}}\right)$ required to achieve a prescribed separation of rotor natural frequency in unactivated and activated states.

\section{Effect of Loss of Stiffness of Composite due to Temperature Rise}

Baz and Chen (1993) have experimentally estimated the loss of stiffness in a composite shaft of Teflon. The storage modulus is found to decrease progressively with increasing temperature. Rogers (1990) has shown a sharp drop in first mode frequency of a graphite/epoxy beam with increasing temperature. There was no tension (phase recovery forces) in the wire. His experiments have shown that the natural frequency of the graphite/epoxy beam decreases from $20 \mathrm{~Hz}$ to about $14 \mathrm{~Hz}$ as the temperature 
increases from $70^{\circ} \mathrm{F}\left(21^{\circ} \mathrm{C}\right)$ to $150^{\circ} \mathrm{F}\left(65.5^{\circ} \mathrm{C}\right)$. This indicates reduction of stiffness of graphite/epoxy composite to about $1 / 2$ of its value at $21^{\circ} \mathrm{C}$. Assuming the same reduction in stiffness of composite $\left(E_{\mathrm{c}}=17.5 \mathrm{GPa}\right)$, the natural frequency for five cases for the Jeffcott and the two-mass rotor on flexible supports are given in Tables V and VI respectively: It may be noted that the results of case 3 (SMA in supports activated and the wires unactivated) remain unaffected for Jeffcott rotor in Tables III and V and for two mass rotor in Tables IV and VI.

In both the Tables V and VI, we note that for small volume fraction $\left(V_{\mathrm{n}}=2 \%\right) p_{5}<p_{1}$, i.e., reduction in $E_{\mathrm{c}}$ dominates over the stiffening effects due to tension in wires and increase in stiffness of rotor supports. As the volume fraction $V_{\mathrm{n}}$ increases, $p_{5}>p_{1}$. As in previous discussion, we shall ignore here the case of $V_{\mathrm{n}}=20 \%$ and $r_{\mathrm{hn}}=4$. Also for $V_{\mathrm{n}}=10 \%, p_{2}<p_{1}$ when $r_{\mathrm{hn}}=1$ and $p_{2}>p_{1}$ when $r_{\mathrm{hn}}=4$. This is primarily because $p_{1}$ is smaller when $r_{\mathrm{hn}}=4$ due to presence of $30 \%$ rubber in the shaft. It may be noted that percentage increases from $p_{1}$ to $p_{3}$ and $p_{2}$ to $p_{5}$ (Tables III-VI) are due to activation of rotor supports. In general, the percentage increase in natural frequency increases with increasing $V_{\text {n }}$. Results of Tables V and VI show that a percentage increase upto $40 \%$ is achievable, even when $E_{\mathrm{c}}$ reduces to half its value due to rise in the temperature of the composite during activation of wires.

\section{Comments on Coast Up/Down Strategies}

Figure 8 illustrates the possible coast up/down strategies. It is obvious that during coast up, the SMA (wires and/or rotor supports) will be initially in activated state and at around a speed of $\omega^{*}$, the SMA will have to be deactivated. During coast down, the situation will be opposite, i.e., first unactivated and then activated as the rotor approaches $\omega^{*}$. The coast up and coast down are shown by arrows in Fig. 8. Since the activation or deactivation of SMA can never be instantaneous where as the coast up or coast down may be rapid, it would be necessary to start the deactivation in case

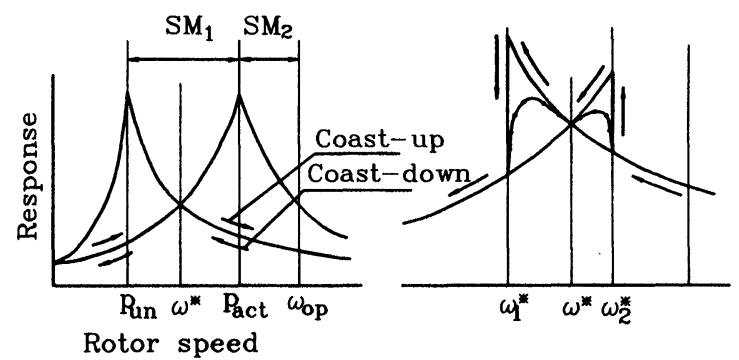

FIGURE 8 Activation strategy for coast up/down.

of coast up at a speed $\omega_{1}^{*}<\omega^{*}$ and start activation in case of coast down at a speed $\omega_{2}^{*}>\omega_{1}^{*}$. The figure shows the coast down path of the rotor if instantaneous deactivation is achieved at $\omega_{1}^{*}$ or $\omega_{2}^{*}$. The actual coast up/down path will be in between the curves of activated and unactivated states as shown in Fig. 8. It may be noted that activation or deactivation of rotor supports will be easier and could be designed to be rapid enough in relation to the rate of coast up/down. The activation/deactivation of wires on rotating shafts is more cumbersome to achieve. Also, since the whole length of wire is embedded in composite shaft or in rubber sleeves, loss of heat and consequent deactivation is difficult to achieve rapidly. From the above considerations, it appears more attractive to introduce SMA in rotor supports. Introduction of SMA wires in the rotor shaft should be considered if a larger value of separation margin $\mathrm{SM}_{1}$ is desired.

\section{CONCLUSIONS}

From the present analysis and the numerical examples, the following general conclusions can be drawn:

1. Jeffcott model of a multimass rotor on flexible supports will be adequate to assess the order (in percent) of separation in rotor natural frequency that can be achieved by activating the shaft wires and/or the rotor supports. However, to estimate the actual value of natural frequency the multi mass rotor model should be used. In an 
inverse problem, formulae (4)-(15) and Figs. 4- 6 can be used iteratively to assess the amount of SMA required to arrive at suitable values of $p_{\text {un }}, p_{\text {act }}, \mathrm{SM}_{1}$, and $\mathrm{SM}_{2}$. The values of both $\mathrm{SM}_{1}$ and $\mathrm{SM}_{2}$ should be greater than $20 \%$.

2. Introduction of SMA wires in a carbon epoxy composite shaft, makes the rotor relatively heavier because of large difference in mass density of SMA and the composite. The effective modulus $E$ in comparison to $E_{\mathrm{c}}$ varies considerably depending upon $V_{\mathrm{n}}$ and $r_{\mathrm{hn}}$. The shaft stiffness is very sensitive to the value of $r_{\mathrm{hn}}$ particularly when $V_{\mathrm{n}}$ is more. The shaft loses its stiffness quite rapidly as the values of $V_{\mathrm{n}}$ and $r_{\mathrm{hn}}$ increase. It is obvious that larger values of $r_{\mathrm{hn}}$ $(>4)$ will restrict $V_{\mathrm{n}}$ in practical designs.

3. Tension in wires due to phase recovery stresses when wires are activated plays a dominant role in raising the rotor natural frequency. A large tension in wires offsets considerably the loss of shaft stiffness due to larger $r_{\mathrm{hn}}$ or $V_{\mathrm{r}}$. However, from practical standpoint a large value of $r_{\mathrm{hn}}$ or $V_{\mathrm{r}}$ is not desirable. The effect of wire tension is most pronounced when the rotor supports are rigid. The effect decreases as the rotor supports become flexible.

4. Results of Tables III and IV show that considerable variation (up to $50 \%$ or more) in natural frequency could be obtained by combined effects of activation of rotor supports, SMA wires in shaft and tension in wires. Variations of the order of $15-20 \%$ could be obtained from a single effect, i.e., activation of wires or activation of supports. In many situations where the coast up/down is not rapid, a smaller separation margin $\mathrm{SM}_{1}$ of an order of $15-20 \%$ may be quite adequate. To achieve a higher separation margin, typically more than $30 \%$, combined activation of shaft wires and rotor supports will be necessary.

5. Comparison of results of Tables V and VI with those of Tables III and IV clearly shows that practical design of shaft is feasible in spite of the effect of loss of stiffness of composite because of rise in temperature due to activation of wires.
However, a larger volume of SMA $\left(V_{\mathrm{n}}>10 \%\right)$ in the rotor is required to offset this effect.

\section{NOMENCLATURE}

\begin{tabular}{|c|c|}
\hline $\mathrm{A}, \mathrm{B}$ & $\begin{array}{l}\text { Static deflection of the system (see } \\
\text { Fig. 2) }\end{array}$ \\
\hline$d_{\mathrm{o}}, d_{\mathrm{i}}$ & $\begin{array}{l}\text { Outer and inner diameters of shaft } \\
\text { cross-section }\end{array}$ \\
\hline$d_{\mathrm{h}}, d_{\mathrm{w}}$ & $\begin{array}{l}\text { Diameters of rubber sleeve and } \\
\text { SMA wires }\end{array}$ \\
\hline$E$ & $\begin{array}{l}\text { Young's modulus, also equivalent } \\
\text { longitudinal modulus }\end{array}$ \\
\hline$I$ & $\begin{array}{l}\text { Second area moment of cross- } \\
\text { section }\end{array}$ \\
\hline$K$ & Effective support stiffness \\
\hline$l, \zeta$ & $\begin{array}{l}\text { Rotor span, distance between } \\
\text { lumped masses/rotor span (see } \\
\text { Fig. 1) }\end{array}$ \\
\hline$m, M$ & $\begin{array}{l}\text { Shaft mass and lumped mass } \\
\text { respectively (see Fig. 2) }\end{array}$ \\
\hline$p$ & Natural frequency of rotor \\
\hline$p_{\mathrm{ss}}, p_{\mathrm{ssm}}$ & $\begin{array}{l}\text { Natural frequency of simply sup- } \\
\text { ported shaft without and with } \\
\text { lumped masses }\end{array}$ \\
\hline$r_{\mathrm{t}}, r_{\mathrm{k}}, r_{\mathrm{m}}$ etc. & $\begin{array}{l}\text { Nondimensional ratios (see Eqs. (5) } \\
\text { and (10)) }\end{array}$ \\
\hline$T$ & Tension in SMA wires \\
\hline$V$ & Volume fraction \\
\hline$\rho$ & Mass density \\
\hline$\mu$ & Poisson's ratio \\
\hline Subscripts & $\begin{array}{l}\mathrm{c}-\text { composite, } \mathrm{n}-\text { NITINOL } \\
\mathrm{r} \text { - rubber } \mathrm{f}-\text { fibre } \mathrm{m}-\text { matri }\end{array}$ \\
\hline
\end{tabular}

\section{References}

Baz, A. and Chen, T., 1993. Performance of NITINOL Reinforced Drive Shafts, SPIE 1917, Smart Structures and Intelligent Systems, 791-808.

Jones, R.M., 1975. Mechanics of Composite Materials, McGraw Hill Book Company, New York.

Liang, C. and Rogers, C.A., 1993. Design of shape memory alloy springs with application in vibration control, Jnl. of Vibration and Acoustics, Transaction of ASME, 115, 129-135.

Nayaga, K. et al. 1987. Active control method for passing through critical speeds of rotating shafts by changing stiffness 
of the supports with use of memory metals, Jnl. of Sound and Vibration, 113(2), 307-315.

Rao, J.S. and Gupta, K., 1984. An Introductory Course on Theory and Practice of Mechanical Vibrations, New Age Publishers, New Delhi, 277-280.

Rogers, C.A., 1990. Active vibration and structural acoustic control of shape memory alloy hybrid composites: Experi- mental results, Jnl. of Acoustical Society of America, 88(6), 2803.

Singh, S.P., Gubran, H.B.H. and Gupta, K., 1997. Developments in dynamics of composite material shafts, Int. Jnl. of Rotating Machinery, 3(3), 189-198.

Tsai, S.W. and Hahn, H.T., 1980. Introduction to Composite Materials, Technomic Inc., Lancaster Pa. 


\section{ait \\ ENERGY MATERIALS}

M A N E Y publishing

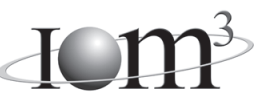

\section{Materials Science \& Engineering for Energy Systems}

Maney Publishing on behalf of the Institute of Materials, Minerals and Mining

The Institute of Materials, Minerals \& Mining

Economic and environmental factors are creating ever greater pressures for the efficient generation, transmission and use of energy. Materials developments are crucial to progress in all these areas: to innovation in design; to extending lifetime and maintenance intervals; and to successful operation in more demanding environments. Drawing together the broad community with interests in these areas, Energy Materials addresses materials needs in future energy generation, transmission, utilisation, conservation and storage. The journal covers thermal generation and gas turbines; renewable power (wind, wave, tidal, hydro, solar and geothermal); fuel cells (low and high temperature); materials issues relevant to biomass and biotechnology; nuclear power generation (fission and fusion); hydrogen generation and storage in the context of the 'hydrogen economy'; and the transmission and storage of the energy produced.

As well as publishing high-quality peer-reviewed research, Energy Materials promotes discussion of issues common to all sectors, through commissioned reviews and commentaries. The journal includes coverage of energy economics and policy, and broader social issues, since the political and legislative context influence research and investment decisions.

\section{CALL FOR PAPERS}

Contributions to the journal should be submitted online at http://ema.edmgr.com

To view the Notes for Contributors please visit: www.maney.co.uk/journals/notes/ema

Upon publication in 2006, this journal will be available via the Ingenta Connect journals service. To view free sample content online visit: www.ingentaconnect.com/content/maney

For further information please contact:

Maney Publishing UK

Tel: +44 (0)113 2497481 Fax: +44 (0)1132486983 Email: subscriptions@maney.co.uk

or

Maney Publishing North America

Tel (toll free): 8662975154 Fax: 6173546875 Email: maney@maneyusa.com

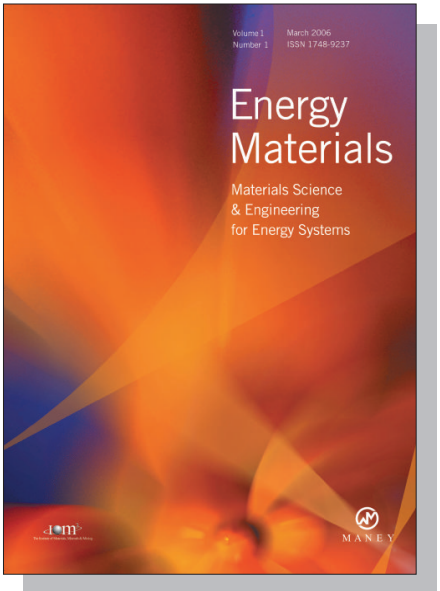

EDITORS

Dr Fujio Abe

NIMS, Japan

Dr John Hald, IPL-MPT, Technical University of Denmark, Denmark

Dr R Viswanathan, EPRI, USA

\section{SUBSCRIPTION INFORMATION}

Volume 1 (2006), 4 issues per year

Print ISSN: 1748-9237 Online ISSN: 1748-9245

Individual rate: $£ 76.00 / U S \$ 141.00$

Institutional rate: $£ 235.00 /$ US $\$ 435.00$

Online-only institutional rate: $£ 199.00 / U S \$ 367.00$

For special $\mathrm{IOM}^{3}$ member rates please email

subscriptions@maney.co.uk

\section{For further information or to subscribe online please visit www.maney.co.uk}



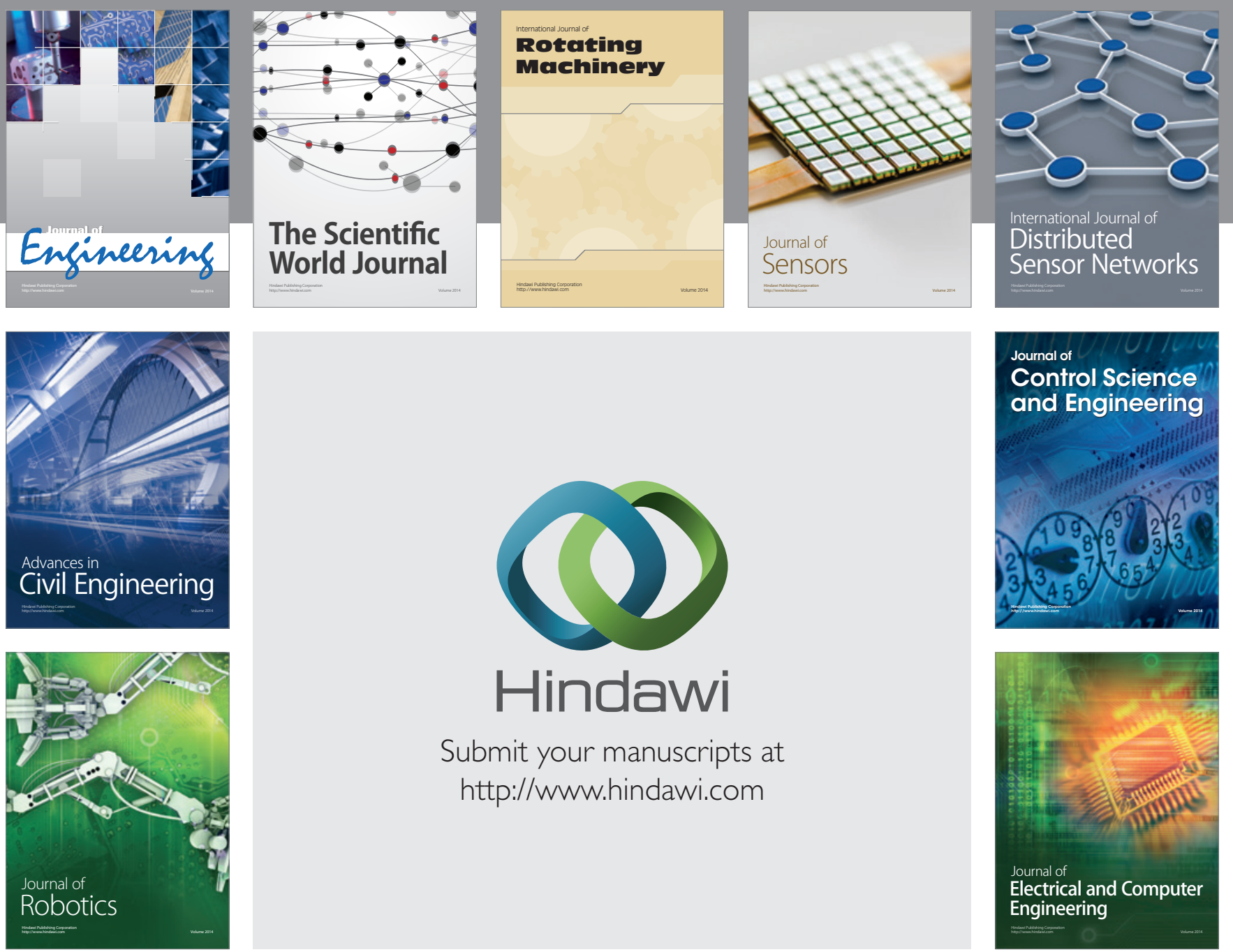

Submit your manuscripts at

http://www.hindawi.com
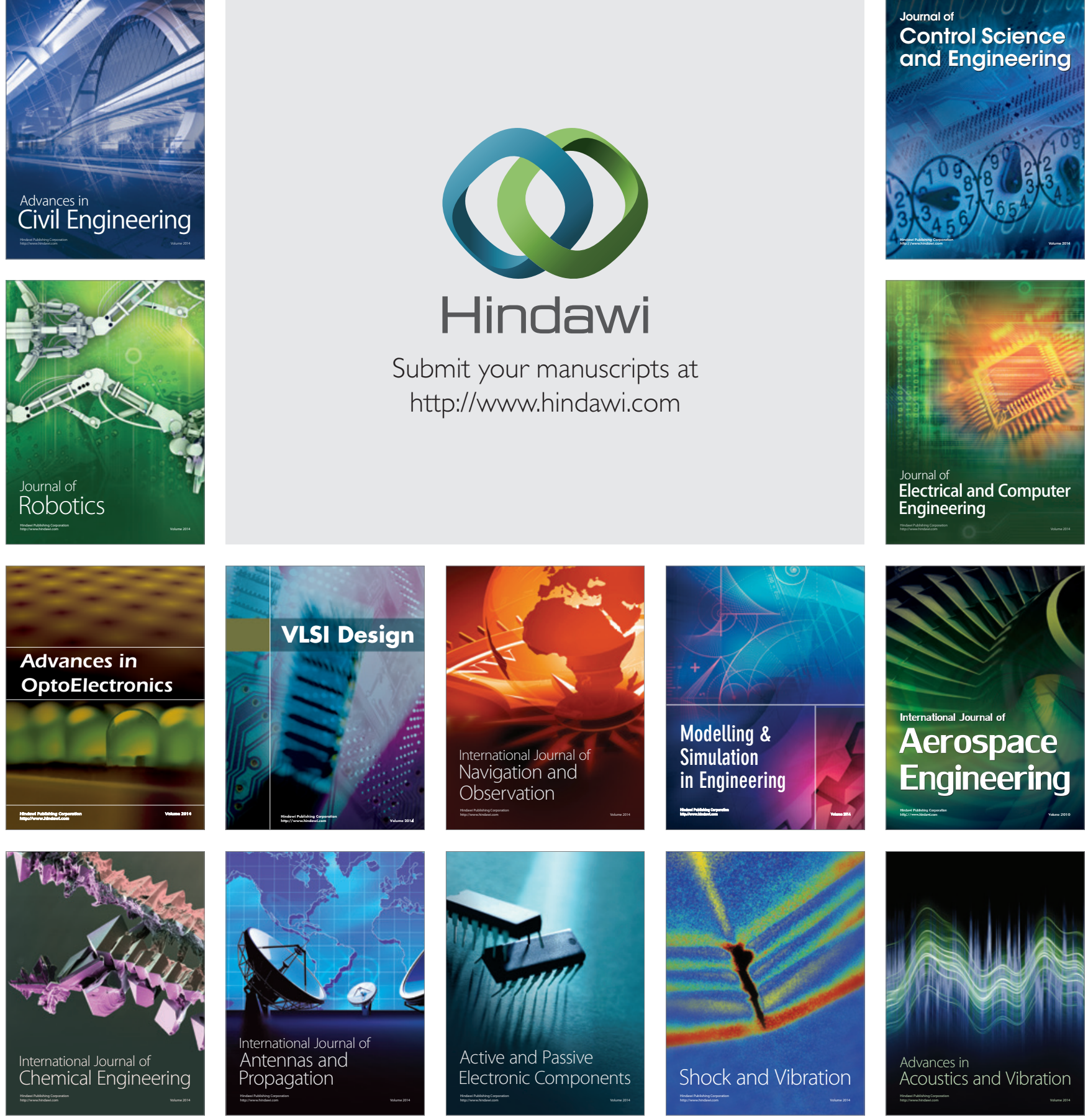